\title{
Time of the Appearance of Cartilage Centers in Human Embryos with Special Reference to its Individual Difference
}

\author{
By \\ Osamu Tanaka \\ Department of Anatomy, Faculty of Medicine \\ Kyoto University Kyoto 606, Japan \\ -Received for Publication, February 23, 1976--
}

The development of the cartilaginous skeleton of the human embryos has been described, illustrated and bibliographically annotated by some authors (Bardeen and Lewis, '01; Lewis, '02; Bardeen, '05; Kernan, '16; Lewis, '20 ; Senior, '29; Streeter, '49; Sensenig, '49; Gray and Gardner, '51 ; Gardner and Gray, '53; O'Rahilly et al., '57; Olivier, '62; Laurenson, '64 ; Elmiger, '66 ; Fricker, '66 ; Tanaka and Nishimura, '69; Andersen, '70; Javor, '75). However, the published data on the time of onset of the appearance of the prenatal cartilage centers are not only meager but also in disagreement presumably because of a relatively small number of the used embryos. Although the approximate time of appearance of the prenatal cartilage centers has been described in those data, accurate information on the degree of its individual difference in the time of appearance of each center is lacking.

Limitations of the two methods available for observing the normal development of the human cartilaginous skeleton may explain the paucity of data in this respect. The two techniques are: (1) histological examination of serial sections, with or without histochemical procedures; and (2) observation of cleared specimens stained with toluidine blue (Romeis, '68) or methylene blue. The majority of the reports on the time of onset of cartilage centers in staged human embryos were based on specimens of histological sections. It appears that this serial sectioning technique yielded incomplete because of the relatively few complete series available. The minority dealt with the methylene blue clearance preparations. In two studies, this technique was employed for observation of cartilaginous skeleton in early human fetuses, (Theiler, '63; Murachi et al., '66).

The purpose of the present study is to establish the standard on the stage of appearance of each cartilage canter by using sufficient 
numbers of the specimens which arose from healthy pregnancy. In view of that the technique of Noback's modification of van Wijhe's method ('16) enables accurate identification of the cartilage centers easily, this method was used.

\section{Materials and Methods}

The materials were four hundred and twenty-two externally normal human embryos ranging from 5.1 to $30.5 \mathrm{~mm}$ in crown-rump length. Their developmental stage ranged from XIII to XXIII of Streeter's horizon (H.) (Streeter, '45, '48) which corresponds to 32 to 52 days of standardized post-conceptional age (Nishimura et al., '68). The detail of the materials is shown in Table 1.

They were obtained through our collaborating obstetricians in Japan who conducted interruption of pregnancy (cervical dilatation and curettage) for social economic reasons. Immediately after the operation, the embryos were fixed in $10 \%$ formalin or Bouin's fluid. $10 \%$ formalin was used for their storage. Through storage, specimens at the stage and over H. XVIII were partially skinned (down to the hands and feet) and eviscerated. Then, all the specimens were subjected to van Wijhe's method ('02) modified by Noback ('16) as follows: they were transferred to acid alcohol $(1 \% \mathrm{HCl}$ in $70 \%$ alcohol) for at least 2 days in the room temperature. Next, they were stained with the methylene blue solution $(0.20-0.25 \%$ in acid alcohol) for at least 3 days, and subsequently returned to several changes of acid alcohol until no more methylene blue comes out. They were passed through 90\% alcohol,

Table 1. List of the embryos studied in the present investigation

\begin{tabular}{c|c|c|c}
\hline $\begin{array}{c}\text { Streeter's } \\
\text { horizon }\end{array}$ & $\begin{array}{c}\text { No. of } \\
\text { embryos }\end{array}$ & $\begin{array}{c}\text { Crown-rump* } \\
\text { Length (mm) } \\
\text { M } \pm \text { S. D. }\end{array}$ & $\begin{array}{c}\text { Approximate } \\
\text { postconceptional } \\
\text { age (days)* }\end{array}$ \\
\hline 13 & 15 & $5.1 \pm 0.15$ & 31.6 \\
14 & 26 & $6.8 \pm 0.08$ & 35.3 \\
15 & 15 & $8.0 \pm 0.07$ & 36.5 \\
16 & 63 & $9.2 \pm 0.08$ & 37.8 \\
17 & 44 & $11.5 \pm 0.13$ & 38.9 \\
18 & 29 & $13.5 \pm 0.36$ & 41.0 \\
19 & 28 & $15.9 \pm 0.30$ & 45.1 \\
20 & 97 & $19.2 \pm 0.26$ & 46.8 \\
21 & 46 & $21.1 \pm 0.26$ & 47.6 \\
23 & 14 & $22.8 \pm 0.53$ & 50.1 \\
\hline
\end{tabular}

* These represent standardized figures established by using the human embryo collection in Department of Anatomy, Kyoto University (Nishimura et al., '68) 
absolute alcohol, absolute alcohol + benzene, benzene (more than two changes until the soft tissues of the material become to be clear) and put into methyl salicylate (oil of wintergreen). It was ascertained that the specimens become transparent and the deeply blue stained cartilage, the blue precartilage showing its indistinct edge and the light blue or colourless remaining tissues are visualized. In early embryos, the notochord also took the methylene blue stain. Correctness of such histological judgment was verified by the observation of two embryos $(\mathrm{H}$. XVI and XVIII) in which the median section was given and one half of the each body is stained and cleared by the above method and the another half is subjected to histological technique by using haematoxylin and eosin. By the results of histological observation, the cartilage centers show a stage of development corresponding to Streeter's phase between three and five (Streeter, '49).

All the cleared specimens were observed with the aid of the binocular and existence of the cartilage centers were determined. In the case of the specimen with equivocal finding the determination was made after dissection of the respective part.

\section{Observations}

The outline of the results on the incidence of cartilage centers is summarized in Table 2-5. Some characteristic findings shown in the tables will be mentioned as follows:

H. 13 Neither cartilage centers nor stained notochord were found.

H. 14 In about the half of the twenty-six specimens, the cervical and thoracic notochord was first stained.

H. 15 The cartilage centers of the scapula first appared in one out of fifteen specimens.

H. 16 The cartilage centers of the occipital arch and humerus were found in two out of the sixty-three specimens. One of these two specimens had the cartilage centers of the first rib, radius, ulna, carpus, hand phalanges, pelvis and metatarsus. The cartilage centers of the metacarpus appeared in $6 \%$ of sixty-three specimens.

H. 17 In this stage, there are most of the cartilage centers of the trunk and appendicular skeleton. The cartilage centers of the vertebral bodies in the cervical, thoracic and lumbar region appeared in $20 \%$ and those of the vertebral arches appeared in $11 \%$ of fortyfour specimens. Simultaneously, the cartilage centers of the 2nd-11th ribs appeared in $16 \%$ and those of 12 th ribs appeared in $12 \%$ of this series. The cartilage centers of the clavicle appeared in two specimens (5\%). The cartilage centers of the humerus, appeared in $84 \%$, those of the radius and ulna appeared in $75-77 \%$, and those of the hand phalanges appeared in the proximal, middle and distal region (25-27\%) 


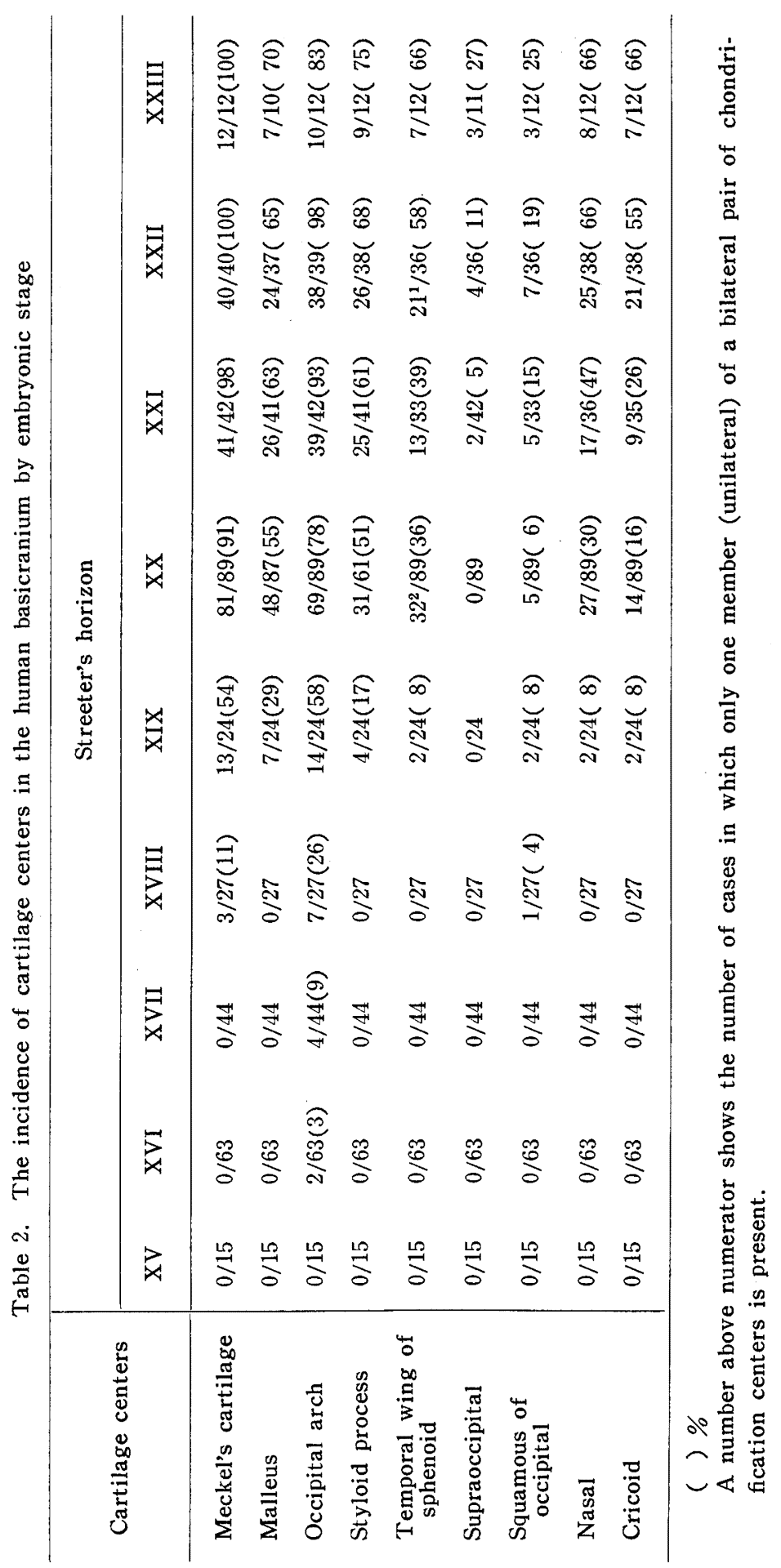









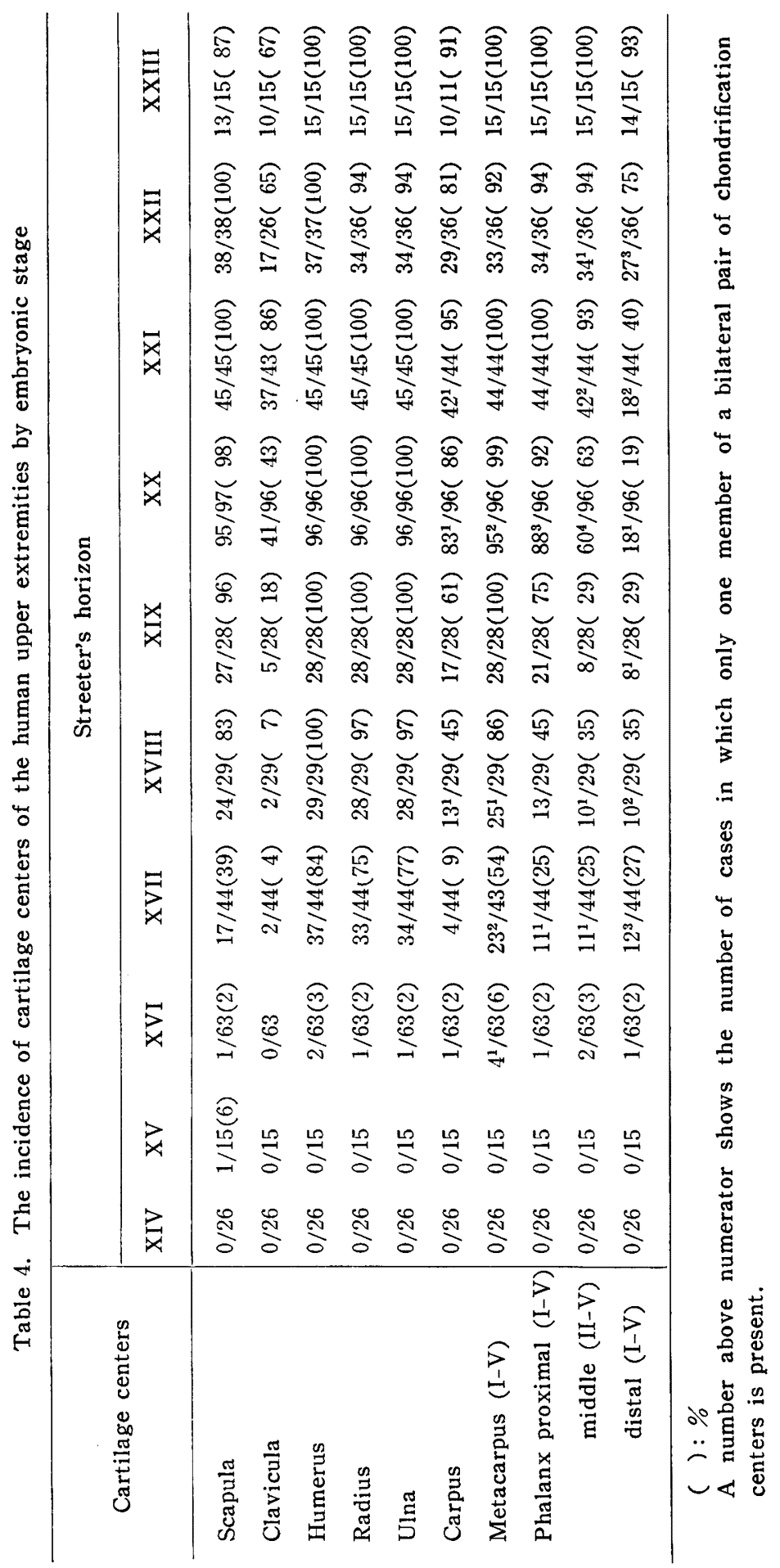




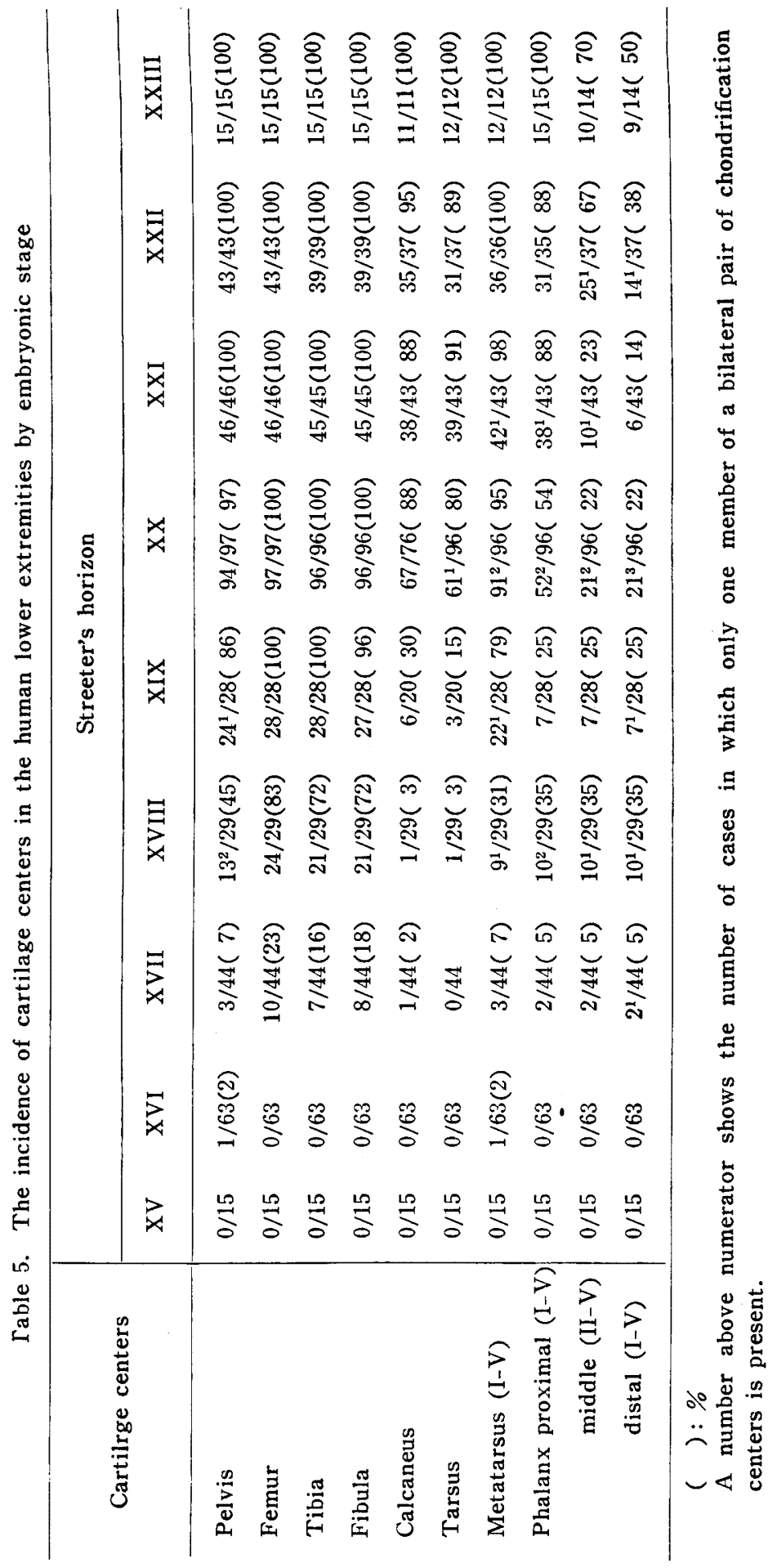


(Fig. 1). In one specimen of twelve in which the cartilage centers were present in the hand phalanges, it was found that the middle phalanx of the 4th finger was not located on the straight line between proximal and distal. In the lower extremity, the cartilage centers of the pelvis appeared in $7 \%$ and these first appeared in the future ilium ossificrtion centers. The cartilage centers of the femur appeared in $23 \%$, those of the tibia and fibula appeared in 16-18\%, and those of the foot phalanges appeared in $5 \%$. The cartilage centers of the metatarsus appeared in $7 \%$ and those of the calcaneus appeared in one out of forty-four specimens.

H. 18 The cartilage center of the facial was present in Meckel's cartilage (11\%). The cartilage centers of the sternum and the squamous of the occipital appeared in one out of twenty-seven specimens. In this stage, the cartilage centers of the humerus come to appear in $100 \%$ and are always found after this stage. The cartilage centers of the 1st-11th ribs appeared in approximately 50\%. The cartilage centers of the tarsus appeared in one out of twenty-nine specimens.

$H$. 19 The cartilage centers of the styloid process, temporal wing of the sphenoid, malleus, nasal and cricoid beganto appear. In this stage, the cartilage centers which appeared in $100 \%$ of the specimens were the 1st-6th ribs, vertebral bodies in the cervical, thoracic and lumbar region, humerus, radius, ulna, metacarpus, femur and tibia. The cartilage centers of the otic capsule first appeared in $3 \%$ of the twenty-four specimens and these centers begin to form a cartilaginous cranial floor with the nasal capsules.

In this stage, the seventh cervical ribs appeared first in two of the twenty-eight specimens and the first lumbar rib in one. The 7 th cervical ribs were bilateral and the first lumbar rib was present on the right side. The cartilage centers of the 12 th ribs appeared in approximately $50 \%$ of the specimens.

H. 20 The cartilage centers of the malleus, styloid process and proximal phalanges of the foot appeared in approximately $50 \%$ of the specimens on each. In the appendicular skeleton, the cartilage centers of the 1st-5th distal phalanges of the hand appeared in $19 \%$, and the same incidence was also shown in those of the foot. The cartilage centers of the 7th-9th ribs and fibula appeared in $100 \%$ of the ninetysix specimens.

Seventh cervical ribs were present in twenty-nine of eighty-nine embryos (32\%), and bilateral first lumbar ribs in three of ninety-seven embryos (3\%). The paired 7th cervical ribs were present in the twentyone embryos. The 7 th cervical rib was present in six embryos on the right side only and two embryos on the left side only.

H. 21 The cartilage centers of the supraoccipital appeared in two of the forty-two specimens. The cartilage centers of the orbito- 
sphenoid and coccygeal vertebral arch first appeared in one of the forty specimens at this stage. The cartilage centers of the nasal appeared in approximately $50 \%$ of the specimens. In this stage, the cartilage centers which appeared in $100 \%$ were those of the ribs except 12th, scapula, metacarpus, proximal phalanges of the hand and pelvis.

Seventh cervical ribs were present in seventeen of forty-six specimens $(37 \%)$. The paired 7 th cervical ribs were present in eleven specimens. The 7 th cervical rib was present in four specimens on the right side only and two specimens on the left side only. In one embryo, it was observed that the cartilage of the bilateral humerus were concurved into medial side.

H. 22 The cartilage center of the nasal septum first appeared in two of the thirty-eight specimens. It begins to ossify in the cartilage of the humerus, radius, ulna, femur and tibia respectively, therefore the deposition of mid-part in the cartilage is observed on those in this stage. The cartilage center of the cricoid and temporal wing of the sphenoid appeared in approximately $50 \%$ of the specimens. In this stage, the cartilage centers of the 1st-12th ribs were present in $100 \%$ of the forty-four specimens (Fig. 5). The cartilage centers which first appeared in $100 \%$ were those of Meckel's cartilage, occipital arch and metatarsus.

Seventh cervical ribs were present in fifteen of forty-four specimens $(34 \%)$. The paired 7 th cervical ribs were present in the twelve specimens. The 7 th cervical rib was present in two specimens on the right side only and one specimen on the left side only. The first lumbar ribs were bilaterally present in two of the forty-four specimens.

H. 23 Most of the cartilage centers of the future skeleton have appeared by this stage. In the chondrocranium, the cartilage centers of the squamous of the temporal appeared in $25 \%$ of the twelve specimens. In the scapula, the cartilage centers were present in all specimens and those of the acromium origin of the scapula were observed on the lateral portion of the clavicle. Both cartilage centers of the 2nd5th middle phalanges of the hand (Fig. 4), and the 1st-5th proximal phalanges of the foot appeared in 100\% of the specimens. In the tarsal, the cartilage centers of the calcaneus and talus appeared in $100 \%$ of the specimens, simultaneously.

Seventh cervical ribs were present in five of fifteen embryos (30\%). The paired 7 th cervical ribs were present in four embryos and unpaired 7 th cervical rib was present in one specimen on the right side only.

The bones of unpaired median presphenoid, 1st and 2nd sternal body, 2nd and 3rd sacral arch, 4th sacral body are present in the precartilage state by stage 23 . The bones which are not yet present in the precartilage state during the stage 23 are the greater horn, 3rd 
and 4 th sternal body, 5th sacral body, 4th and 5th sacral arch and patella.

The majority of the cartilage centers are present in the whole body at $H .23$, and many of them first appear between H. 17 and H. 19.

The unilateral presence of one of a pair of bilateral cartilage centers is observed during the time when these centers normally appear after the time of their normal appearance. Asymmetry in the time of appearance of bilateral cartilage centers was observed on the ribs, hand and foot in the main (Table 3-5).

The cartilage centers of the 1st-12th thoracic vertebral body and arch appear in 11-20\% almost simultaneously at $\mathrm{H}$. 17. The cartilage centers of 1 st-11th ribs appear in $16 \%$ almost simultaneously at $H .17$, however, those of the 12th ribs appear later.

A comparison of the time of appearance of the cartilage centers of the upper extremities with those of the lower extremities prompts some general statements. The cartilage centers of the upper extremities appear earlier than those of the lower extremities. The cartilage centers of the femur, tibia and fibula appear one stage later than those of the humerus, radius and ulna. The cartilage centers of the hand invariably appear before their counterparts in the foot. Thus, the 1st5 th metacarpal centers appear in $54 \%$ at $H .17$, but the 1 st-5th metatarsal appear in $7 \%$ at the same stage. The cartilage centers of the 1st-5th proximal phalanges of the hand appear in $25 \%$ at $\mathrm{H}$. 17 , but those of the foot appear in $5 \%$ at the same stage. In the middle and distal phalanges of the hand and foot, the time of appearance of the cartilage centers of those are similar to the above findings.

Generally, variation in the appearance of the cartilage centers is small. It was found that one embryo at $\mathrm{H}$. 16 is progressive in the chondrification of the skeletal components. The unilateral or bilateral 7th cervical rib are present from H. 19 and the unilateral or bilateral lumbar rib are present from the same stage. On the basis of the observation on the 7th cervical rib, it is suggested that the 7 th cervical ribs, when present, are usually bilateral. (Table 3)

\section{Discussion}

A comparison of the time of appearance of the some of the cartilage centers between the present stady and the report by Noback and Böving ('62) is shown in Figure 6. The literature quoted is based on the histological observations of serially sectioned specimens, and denote the time of appearance of the cartilage centers in terms of a body dimension; Streeter's horizon, crown-rump length (CRL) and embryonic age.

The present study indicated that the cartilage centers of Meckel's 

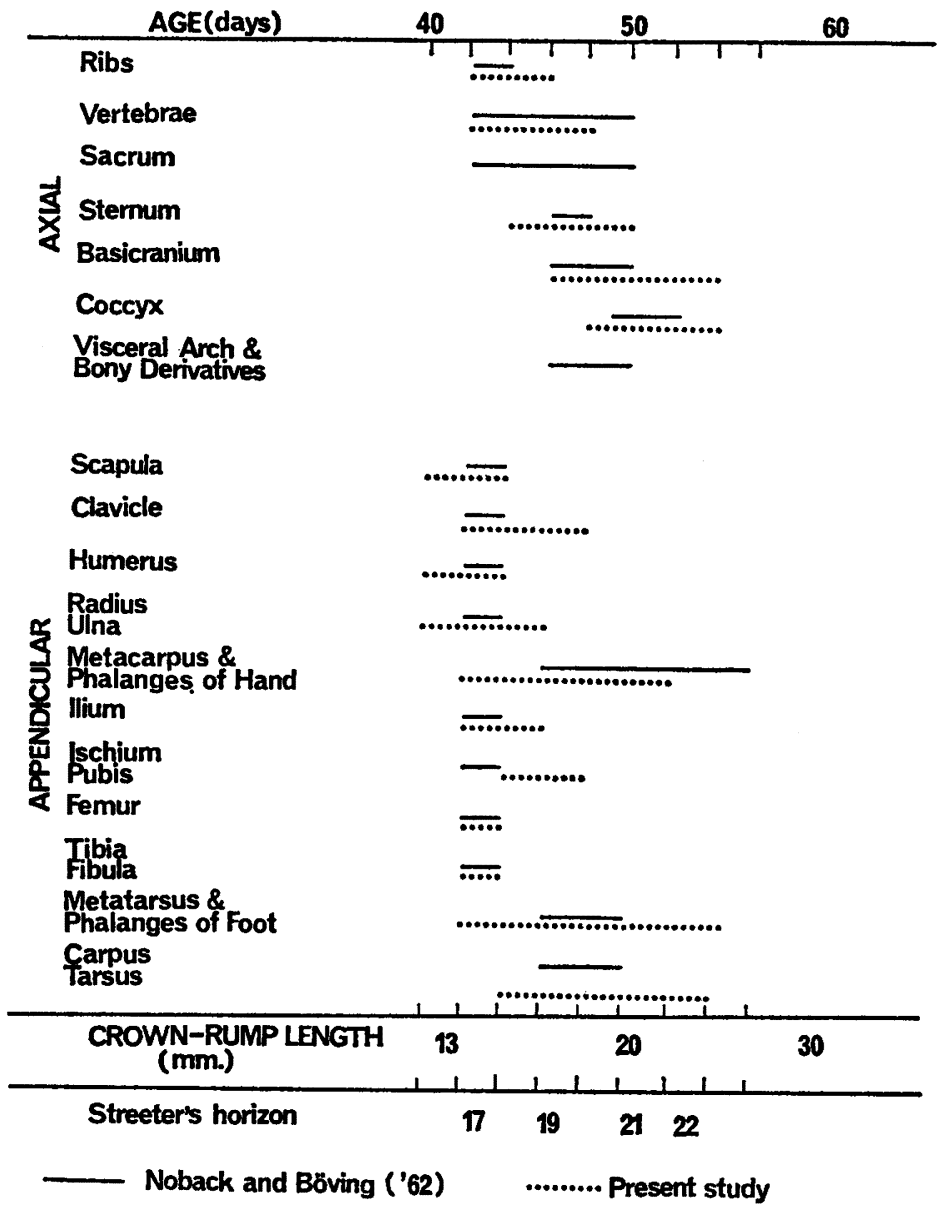

Fig. 6. A comparison of the present study with the data of the previous study on the time of onsent of cartilage centers

cartilage appeared first at $H .18$ and this finding agreed with the findings of the previous investigators (CRL 12-16 mm, Röse, 1891 ; CRL 12-13 mm, Fawcett, '05 ; CRL $13.7 \mathrm{~mm}$, Kaneta, '61 ; CRL $14 \mathrm{~mm}$, O'Rahilly and Gardner, '72; H. 18, Tanaka and Nishimura, '73; CRL $13 \mathrm{~mm}$, Durst-Zivković and Davila, '74).

The cartilage center of the occipital arch, located on either side of the foramen magnum (Patten, '68), appears at stage 17-18 and this is earlier by one stage than the findings of Kernan ('16) and Lewis ('20).

In $\mathrm{H} .17$ embryos, the cartilage centers of the shaft of the 1st11 th ribs are present in $16 \%$ of forty-four specimens, however, Sensenig ('49) observed on those at the base of the rib shaft in CRL $15 \mathrm{~mm}$, embryos (Horizon 18). The sequence of a rib extends from lst toward 
12th and it takes comparatively long period that the cartilage centers of 1st-12th rib are present in all specimens. According to Lewis ('02) and Bardeen ('05), the cartilage centers of the first seven ribs appeared in CRL 13 or $14 \mathrm{~mm}$ (Horizon 17) and Sensenig ('49) found that in 25 $\mathrm{mm}$ embryos (Horizon 22) the first rib is chondrified throughout its extent: and in $30-35 \mathrm{~mm}$ (Horizon 23 or older embryos) the first seven ribs are chondrified throughout. However, chondrification of the first seven ribs has seen in throughout its extent in all specimens of H. 20.

The early development of the vertebrae and the ribs is of particular interest because of the interesting manner in which they develop. According to Arey ('65), centers of chondrification begin to appear in the seventh week in the highest vertebrae, and quickly follow at successively lower levels. The both precartilage and cartilage centers of the vertebral bodies appear in stage 17-18 and the present observations of those are similar to the findings of the previous investigators (CRL, $11 \mathrm{~mm}$, Lewis, '02 ; CRL, $14 \mathrm{~mm}$, thoracic, Bardeen, '05 ; CRL, 11$12 \mathrm{~mm}$, Horizon 17, Sensenig, '49 ; CRL, $13.5 \mathrm{~mm}$, Popova-Latkina, '67). In H. 19 embryos chondrification is well under way throughout the vertebral bodies and these patterns agree with the findings of Sensenig ('49). The cartilage centers of vertebral arches appear slightly later than those of vertebral bodies, and the present observations agree with above authors.

As regards the development of the clavicle the views are conflicting, and many hypotheses have been advanced (Bruch, 1853; Mall, '06; Fawcett, '13; Hanson, '20; Fischel, '29; Fazzari, '34; Florentain and Castelain, '35 ; Zawisch, '53 ; Koch, '60 ; Andersen, '63 ; Gardner, '68). According to Gardner ('56), Hamilton and Mossman ('72), and O'Rahilly and Gardner ('72), the clavicle is a long bone which begins in membrane and secondarily develops growth cartilages. By the present observations, cartilage centers of clavicle appear in H. $17(4 \%)$ at medial end and $\mathrm{H} .21(86 \%)$ at both ends, however, the lateral cartilage center is smaller than the medial. By CRL $26 \mathrm{~mm}$ (Horizon 22) embryos, cartilage is definitely present at both ends (Gardner, '56), present study detects that the maximum incidence of appearance of those is $86 \%$ in H. 21 and after this stage this incidence decreases until H. 23.

There are some literatures on the development of the scapula in human embryos (Hagen, '00; Hertwig, '06; Bardeen, '10; Rutherford, '14 ; Dijkstra, '23 ;Nauck, '26 ; Fischel, '37 ; Ciardi-Dupré, '42 ; Hochstetter, '52; Gardner and Gray, '53; Zawisch, '54 ; Olivier, '62 ; Andersen, 63 ; Elmiger '66; Tanaka, '73). The cartilage centers of the scapula appear between H. 16 and 18, and this result is similar to the findings of the time of appearance of those in above literatures. This individual difference may be large. The cartilage centers of the lamina of the scapula and the most axillary portion of the spina (spinal pillar) appear 
before the coracoid process and the acromion and the present observations agree with Elmiger ('66).

Textbooks state that the humerus, radius and ulna chondrify at the end of sixth week or early in the seventh week. The cartilage centers of humerus appear in H. 16 and become first to be $100 \%$ at H. 18 among those of the cartilaginous elements of upper limb. Bardeen and Lewis ('01) found that the core of the shaft of the humerus is of hyaline cartilage in the CRL $11 \mathrm{~mm}$ and $15.5 \mathrm{~mm}$ embryos that they studied. Lewis ('02) studied the early development of the upper limb in man and found the cartilage in the humerus at 10.5 to $11 \mathrm{~mm}$, and Olivier ('62) saw it for the first time at $13 \mathrm{~mm}$ with use of reconstructions. O'Rahilly et al. ('57) published an excellent paper on the chondrification in hand and feet of staged human embryos. They found that early chondrification of humerus was noted in one out of ten embryos at horizon 16, and showed horizons in which first appearance of skeletal

Table 6. Horizon in which first appearance of chondrification in skeletal limb elements is usually found (A comparison of the present study with the data of the previous one)

\begin{tabular}{|c|c|c|}
\hline $\begin{array}{l}\text { Skeletal elements in the } \\
\text { extremities }\end{array}$ & O'Rahilly et al. ('57) & Present study* \\
\hline \multicolumn{3}{|l|}{ Upper } \\
\hline Humerus & $16-17$ & $17-18$ \\
\hline Radius & 17 & $17-19$ \\
\hline Ulna & $17-18$ & $17-19$ \\
\hline Hand Carpus & & $20-22$ \\
\hline Carpus except pisiform & $18-19$ & \\
\hline Pisiform & $19-21$ & \\
\hline Metacarpus & $17-18$ & $18-19$ \\
\hline Phalanges Proximal & $18-19$ & $19-21$ \\
\hline Middle & $19-20$ & $20-23$ \\
\hline Distal & $20-21$ & $22-23$ or later \\
\hline \multicolumn{3}{|l|}{ Lower } \\
\hline Femur & $17-18$ & $18-19$ \\
\hline Tibia & $17-18$ & $18-19$ \\
\hline Fibula & $17-18$ & $18-20$ \\
\hline Foot Tarsus & $18-19$ & $20-23$ \\
\hline Metatarsus & $18-19$ & $19-22$ \\
\hline Phalanges Proximal & 20 & $21-23$ \\
\hline Middle & 21 & $22-23$ or later \\
\hline Distal & $21-23$ & $23^{* *}$ \\
\hline
\end{tabular}

* Present study shows horizon in which the chondrification centers appear in the incidence between about $70 \%$ and $100 \%$ except distal phalanges of foot.

** The chondrification centers appear in $50 \%$ at $\mathrm{H} .23$. 
limb elements is usually found. A comparison of the results of the present study with the findings of them is shown in Table 6 . On the time of appearance of the centers in humerus, the present study results in $84 \%$ at H. 17 . Another study of the early embryonic development of the humerus is reported in some papers (Faldino, '21; Hesser, '26; Haines, '47 ; Streeter, '49; Gray and Gardner, '51; Gardner and Gray, '53; O'Rahilly et al. '59; Andersen, '62b; Andersen, '70). Gray and Gardner ('69) showed a datail of the cartilage in relation to a primary bony collor in the humerus with use of histological sections of human embryos and a primary bony collor was present before the embryonic period, and in a $27 \mathrm{~mm}$ embryo it extended for nearly one-third of the length of the humerus. By the present study, the blue collor deposition of the cartilage centers is observed in outer region of the humerus at H. 22 and it seems to begin to ossify in the cartilage of the humerus.

According to Gray and O'Rahilly ('57), chondrification begins in the radius of most specimens at horizon $17(11-13.5 \mathrm{~mm})$, and ulna is chondrifing in many. The cartilage centers of the radius and ulna appear between horizon 16 and 19, and both cartilage centers of those appear in the degree of the nearly same incidence by the present study. This result differs slightly from those of O'Rahilly et al. ('57). (Table 6). This different criterion for the onset of chondrification may occur in order to create the incidence of $70-100 \%$ in the current study.

According to Haines ('47), by $14 \mathrm{~mm}$ embryos the carpal elements were chondrified, however, O'Rahilly et al. ('57) studied such early blastemal stage was generally unfavorable for distinguishing the individual carpal elements. They stated that the various elements of the skeleton of the hand began to chondrify usually between $\mathrm{H}$. 18 and 21 (aprroximately during the sixth ovulation week) (11-24 mm) (Table 6). They found three embryos out of 21 in which chondrification had began in the hamate and capitate at H. 17. However, in the present study, the cartilage centers of those are observed first in one embryo out of 63 at H. 16. According to O'Rahilly ('54), the centrale carpi was found as a free element in specimens between $16 \mathrm{~mm}$ and $19 \mathrm{~mm}$, and a variable degree of its fusion with the scaphoid had occurred in the specimens between $22 \mathrm{~mm}$ and $29 \mathrm{~mm}$. By the present study, the cartilage centers of the centrale was found to appear first in H. 18 (the smallest crown-rump length $13.5 \mathrm{~mm}$ ), and it begins to fuse with the scaphoid in majority of embryos in H. 20 and 21 (Fig. 3). The latter finding is similar to those of Gray et al. ('57). I confirmed that the carpal elements begin to chondrify in a definite following sequence as pointed out by Senior ('29): the sequence was (1) hamate, (2) capitate, (3) trapezoid (multangulum minus), (4) triquetrum, (5) trapezium (multangulum majus), (6) scaphoid (navicular and centrale), (7) lunate, and (8) pisiform. Streeter ('29) used the order of chondrification established 
by Senior ('29) for the staging human embryos.

According to Senior ('29), the hamate, capitate, and metacarpals 2 to 4 chondrify "almost simultaneously" in the specimens of his first stage. O'Rahilly et al. ('57), however, indicated that within this first stage, metacarpals 3 and 4 chondrified first. The present study revealed that in H. 17 embryos, the cartilage centers of the 5th metacarpals appear almost simultaneously with those of the 2nd-4th in three out of 43 embryos. O'Rahilly et al. ('57) recognized in their three embryos at H. $18(11.7-18.0 \mathrm{~mm})$ chondrification of the first metacarpals.

Lewis ('02) stated that at H. 17 proximal phalanges of the hand were chondrifying except that of the thumb, but O'Rahilly et al. ('57) found chondrification beginning in the proximal phalanx of the thumb also at this stage. In the present study, the chondrification centers of the proximal phalanx of the thumb are present in one out of 44 embryos at $\mathrm{H} .17$, three out of 29 embryos at $\mathrm{H}$. 18, and about a half number of the embryos at H. 19. Bardeen and Lewis ('01), and Lewis ('02) concluded that of the distal phalanges only thumb was chondrifying in H. 21 embryo, and O'Rahilly et al. ('57) found chondrification of the distal phalanges of the 2nd to 4th digits in H. 20-21 embryos, but were uncertain about that of the 5th finger. The present author observed the cartilage centers in the distal phalanges of the 1st to 4 th digits in five out of 96 embryos at H. 20, and those of the 1st to 5th digits, in one embryo at the same horizon. It has been generally recognized that the digits begin to chondrify in proximo-distal sequence (Henke and Reyher, 1874, Hagen, '00 ; Lewis, '02 ; Hesser, '26 ; Senior, '29; Gray and O'Rahilly, '57; Hamilton and Mossman, '72). The data from the present study indicate the same sequence, i.e., the cartilage centers of proximal phalanges are present in $100 \%$ at $\mathrm{H}$. 21, and those of middle phalanges in $100 \%$ at $\mathrm{H}$. 23 , but those of distal phalanges in $93 \%$ at $\mathrm{H} .23$.

Bardeen ('05) studied the early development of the human skeleton of the posterior limb and found tbat the initiation of formation of the cartilage in the ilium, ischium and pubis was indicated in $11 \mathrm{~mm}$ embryo, and in $14 \mathrm{~mm}$ embryo the cartilage of three bones were distinct. He gave that during the stage from 15 to $20 \mathrm{~mm}$ in crown-rump length, there occurred a rapid development of those cartilages. The references on chondrification of the pelvis was made by Strayer ('43), Haines ('47), Gardner and Gray ('50), and Andersen ('62a), where they concentrated to the development of the hip joint. According to Gardner and Gray ('50), the skeleton of the hip joint consisted largely of condensed blastemal tissue in a $12 \mathrm{~mm}$ embryo and in the next week embryos of crown-rump length $14-15 \mathrm{~mm}$, the ilium, ischium, and pubis still consisted of precartilage. They found that the pubis was separated from the ischial and iliac cartilages by dense blastemal tissue in one 
of five specimens of 22 to $25 \mathrm{~mm}$ in length. Schunke ('38) studied the development of the sacro-iliac joint and found the sacral and iliac cartilages were well differentiated at $25 \mathrm{~mm}$ crown-rump length. Andersen ('62a) found that the central area of the acetabulum consisted of hyaline cartilage with exception of $\mathrm{Y}$-shaped structure which separated the three coxal elements at $20 \mathrm{~mm}$ crown-rump length. Fricker ('66) saw that the cartilagenous rudiments of the ilium, ischium and pubis appeared in the crown-rump length between $12 \mathrm{~mm}$ and $17 \mathrm{~mm}$, and these grew together in succession with the exception of the blastemfilled indentation situated between the rudiments of the ischium and pubis in the stage between $17 \mathrm{~mm}$ and $22 \mathrm{~mm}$ crown-rump length. Laurenson ('64) studied the development of the ilium by using the five phases in chondrogenesis, described by Streeter ('49) for the humerus, and reported that young cartilage cells appeared in H. 19 (17-20 mm, $38-40$ days), both phase 1 and phase 2 cells in H. 20 (21-23 mm, 40-42 days), and phase 3 cartilage cells in H. 21 (22-24 mm, $42-44$ days). The present author found that the cartilage centers of the pelvis, namely the primitive iliac cartilage, appear first as a rounded plate at $\mathrm{H} .16$, however, only one of 63 embryos at this stage, and increase its incidence after this stage. The cartilage centers of the ischium and pubis at their early stage were found to be mere rounded masses lying in the center of their precartilages of a flat plates. It was shown that the centers of the ischium are present in three of 29 embryos at H. 18, (Fig. 2) but those of the pubis in one of them. After H. 22, those of the ilium, ischium and pubis are observed always as three elements in the pelvis. The above mentioned pattern of the onset of the cartilage centers in the pelvis is almost similar to that of Bardeen ('05) who reconstructed the pelvis of the human embryo. Salathe ('70) studied the development of the ilium in human embryos and fetuses, and draw attention to the great similarity of the developmental pattern between the ilium and scapula.

Bardeen ('05) found that in a $11 \mathrm{~mm}$ embryo, the femur was chondrifying, and this cartilage consisted of a bar largest at the knee whence it tapered off toward the hip, and that at $14 \mathrm{~mm}$ it had a simple, rounded head. Gray and Gardner ('50) found that chondrification of the femoral blastema was already complete in an embryo of $12 \mathrm{~mm}$ in crown-rump length, and in the tibia the cartilage extended further distally than in the fibula. O'Rahilly et al. ('57) found that in the most-advanced limbs of 21 embryos at H. 17, the entire femur was chondrifying, and the centers of chondrification were present in the tibia of some specimens, the fibula of only two. According to Gardner and O'Ranilly ('68) who studied the early development of the knee joint in human embryos, the femur, tibia and fibula had begun to undergo chondrification by stage 18. A comparison of the results of the present 
study on chondrification of the lower limb elements with the findings of O'Rahilly et al. ('57) is shown in Table 6 .

Several authors of early studies have reported chondrification in the foot beginning in the embryos of about 14 to $21 \mathrm{~mm}$ in crownrump length (Henke and Reyher, 1874 ; Baur, 1886 ; Bardeen and Lewis, '01; Bardeen, '05; Martin, '29 ; Hintzsche, '30; Haines, '47 ; Trolle, '48). Schomburg ('00) classified four periods in the development of the skeleton of the foot in human embryos, and his results were discussed by Bardeen ('05). At cartilaginous period after the perichondrium period in which Schomburg described, Bardeen ('05) found that at H. 17 (crown-rump length $18 \mathrm{~mm}$ ), the talus, calcaneus, navicular, three cuneiforms, cuboid and metatarsals laid less spread apart than at an earlier stage (crown-rump length $14 \mathrm{~mm}$ ). O'Rahilly et al. ('57) reported that the skeleton of the foot was blastemal by H. 17 to 18 , and the various elements began to chondrify between $\mathrm{H}$. 18 and 23 (from approximately 5.5 to 7 weeks), or later. The present author found that the cartilage centers of the foot are present in between $\mathrm{H}$. 18 and 23, or later, and in the calcaneus its onset is earlier than in the tarsus at H. 17. The tarsals like those of the carpal elements, began to chondrify in a definite sequence as pointed out by Senior ('29), and the sequence was (1) cuboid, (2) calcaneus, (3) talus, (4) cuneiform 3, (5) cuneiform 2, (6) cuneiform 1, (7) navicular, and O'Rahilly et al. ('57) confirmed these results, with few variations. The present author found that the cartilrge center of the calcaneus is present in one of 44 embryos at H. 17, and it is earlier one horizon than those of the cuboid. As pointed out by O'Rahilly et al. ('57), it is interesting in a comparison of the ossification in the tarsals that the cuboid is the first element to chondrify, but the calcaneus and talus are first ossify (Francis and Werle, '39; Noback and Robertson, ' 51 ; Kjar, '74). In the present study, the cartilage center of the first element appears in some embryos at H. 16-20, and they may appear in accordance with the sequence of the onset of the ossification centers.

Bardeen ('05) found that chondrification of the metatarsals was present in an embryo of $14 \mathrm{~mm}$ crown-rump length, and O'Rahilly et al. ('57) found that chondrification was present in the 2nd to 5 th metatarsals in the minority of 17 embryos at $\mathrm{H} .18$ and that of the 1st metatarsal was first observed at H. 19. Also, the present author recognized that the cartilage centers of the metatarsals appear during the period from H. 16 to H. 22, that is, the earliest stage is younger by two stages than that reported by them.

It is also generally agreed that the digits of the foot, like those of the hand, chondrified in a proximodistal sequence ( $O^{\prime}$ Rahilly et al., '57). O'Rahilly et al. ('57) found that first appearance of chondrification in the proximal phalanges of the foot usually occurs at H. 20, 
middle phalanges at $H .21$, and distal phalanges at H. 21-23 (Table 6). In the present study, the cartilage centers of the proximal, middle and distal phalanges of the foot are first observed at H. 18, but at H. 20 the incidence of the proximal phalanges accounts for $54 \%$ while that of both the middle and distal phalanges is the same value of $22 \%$ at H. 20, and at H. 23 still less than 100\% (the middle phalanges: $70 \%$; the distal phalanges: $50 \%$ ).

There are no reports about the chondrifying 7 th cervical rib, but are some papers about the ossification centers of that rib. It has been known that the 7 th cervical rib is found frequently during prenatal period. In the earliest paper by Gruber (1869), it was described the 7th vertebrae often carried a short "cervical" rib in human fetuses. The incidence of the human cervical ribs was reported to be two out of 14 fetuses ranging from 57 to $110 \mathrm{~mm}$ crown-rump length (Mall, '06), 49 out of 91 fetuses ranging from 58 to $400 \mathrm{~mm}$ (Teissandier, '44), 34 out of 79 fetuses ranging from 57 to $235 \mathrm{~mm}$ (Noback and Robertson, '51). The similar study by Tanaka and Nishimura ('72) revealed also a high incidence of those ribs (24 cases out of 94 fetuses ranging from 54 to $280 \mathrm{~mm}$ crown-rump length).

In the present study, it was found that the earliest stage showing the 7 th chondrifying cervical ribs was $H .19$ and the highest incidence of those was $37 \%$ at $H$. 21. This incidence is slightly higher than that of Tanaka and Nishimura's observation ('72) on the ossification centers of those ribs. On the basis of the present study as well as that of the previous investigations such as Noback and Robertson ('51), it can be concluded that the 7th cervical ribs, when present, are usually bilateral. As to the lumbar ribs, it is noted that its incidence is remarkably lower than that of the cervical ribs as shown in the Table 3 and this finding almost coincides with the report on ossified lumbar by Noback and Robertson ('51).

The presence of only one member of the bilateral pair of ossification centers of human skeleton during prenatal and neonatal life has been reported occasionally (Macalister, 1884 ; Mall, '06, Borovanský, '31 ; Menees and Holly, '32; Noback, '43; Teissandier, '44; Noback and Robertson, '51). There is only one report, however, about asymmetry regarding chondrification centers of human skeleton: Bardeen ('04) described a detail of the numerical vertebral variation at the period of chondrification in human embryos ranging from 13 to $50 \mathrm{~mm}$ crownrump length, and indicated the rare existence of some asymmetric lumbar vertebrae. However, this report did not include the asymmetry in the onset of chondrification of the vertebral columns. The present author found that there are a number of specimens which show the unilateral onset of the cartilage centers of the vertebral arches, ribs, pelvic girdle, carpals, metacarpals, metatarsals, and distal phalanges of 
both hands and feet. These results agree with those on ossification centers by Noback and Robertson ('51).

In conclusion, the present study established the approximate standard of the time of appearance of the cartilage centers in human embryos. The significance of such standard will be to provide us with diagnosing various bone defects and variations in early stages. In addition, the experience of preparation of many cartilage clearly stained specimens led to the conclusion that this technique is useful in screening malformed cartilaginous skeleton such as the case reported by Dziallas ('70) who found the deformity of the long cartilaginous extremities by means of the reconstruction method in a $18 \mathrm{~mm}$ crownrump length embryo showing craniorhachischisis.

\begin{abstract}
Methylene blue clearance preparations of 422 externally normal embryos were examined for study of individual difference in chondrification. These human embryos, at stages ranging from 13 to 23 of Streeter's horizon ( 5.1 to $30.5 \mathrm{~mm}$ crown-rump length), that is, at five to eight weeks postconceptional age, were obtained from healthy pregnant women subjected to induced abortion by curettage.

The stage of the onset of cartilage centers which appear in $100 \%$ by horizon 23, will be mentioned in the sequence of the stage of the first appearance: The cartilage centers of the humerus appear between horizons 16 and 18 . Those of the 1st ribs, vertebral bodies, radius, ulna, and metacarpals appear between horizons 16 and 19. Those of the presacral vertebral arches, scapula, carpals, proximal phalanges of the hand and pelvis appear between horizons 16 and 21. Those of the metatarsals appear between horizons 16 and 22 . Those of the 2nd-6th ribs, femur, and tibia appear between horizons 17 and 19. Those of the 7 th-9th ribs and fibula appear between horizons 17 and 20 . Those of the 10th-11th ribs appear between horizons 17 and 21, and the 12th ribs between horizons 17 and 22. Those of the proximal phalanges of the foot and calcaneus appear between horizons 17 and 23. Those of the Meckel's cartilage appear between horizons 18 and 22, and of the tarsus between horizons 18 and 23 .

Next, the stage of the first appearance of the cartilage centers which appear only occasionally by horizon 23 will be given as follows: the occipital arch and distal phalanges of the hand, 16 ; the middle and distal phalanges of the foot, 17; the squamous of the occipital, 18; the malleus, styloid process, temporal (greater) wing of sphenoid, nasal, and cricoid, 19 ; the supraoccipital, 21.

The above mentioned data differ somewhat from the findings of the previous investigators. Moreover, 37 embryos with asymmetry,
\end{abstract}


regarding the appearance of some cartilage centers of bilateral pair were found.

The incidence of the 7 th cervical rib was $7 \%$ in horizon $19,32 \%$ in horizon $20,37 \%$ in horizon $21,34 \%$ in horizon 22 , and $30 \%$ in horizon 23. The 7th cervical ribs, when present, were usually bilateral. The lumbar rib (unilateral or bilateral) was observed on the incidence betweeen $4 \%$ and $7 \%$ at horizons from 19 to 23 .

\section{Acknowledgments}

The author is indebted to Dr. Hideo Nishimura for his valuable advice and encouragements, to the cooperating obstetricians in Japan for supplying the materials. This study was supported by grants from the National Institute of Child Health and Human Development (HD 01401-01-06), the Association for the Aid of Crippled Children, New York, the Population Council, New York, World Health Organization (Human Reproduction Unit) and Japanese Ministry of Health and Welfare (Section of Child and Maternal Welfare).

\section{References}

Andersen, H.: Histochemical studies of the development of the human hip joint. Acta Anat., 48 : 258-292, 1962a.

Andersen, H.: Histochemical studies of the histogenesis of the human elbow joint. Acta Anat., 51: 50-68, 1962b.

Andersen, H.: Histochemistry and development of the human shoulder and acromioclavicular joints with particular reference to the early development of the clavicle. Acta Anat., 55: 125-165, 1963.

Andersen, H.: Histochemical investigations on development of the joint and bone systems of the human foetus during the first half of the prenatal period. Thesis. Univ. of Copenhagen, 1970.

Arey, L.B.: Development anatomy. A textbook and laboratory manual of embryology. W. B. Saunders Co., Philadelphia and London, 1965.

Bardeen, C.R. and W.H. Lewis: The development of the limbs, body wall and back. Am. J. Anat., 1: 1-36, 1901.

Bardeen, C.R.: Vertebral variation in the human adult and embryo. Anat. Anz., 25 : 497-519, 1904.

Bardeen, C.R.: Studies of the development of the human skeleton. Am. J. Anat., $4: 265-302,1905$.

Bardeen, C.R.: Der Entwicklunsgeschichte der Menschen. In Keibel und Mall's Hb. Bd. 1, Hirzel, Leipzig, 1910.

Baur, G.: Bemerkungen über den "Astragalus" und das “Intermedium tarsi " der Säugetiere. Morphol. Jahrb., 11: 468-483, 1886.

Borovanský, L.: Osifikase hrdni kosti a jeji rust u cloveka. Rozpravy II tridy Ceske Akademie, $40: 1-30,1931$.

Bruch, C.: Uber die Entwicklung der Clavicula and die Farbe des Blutes. Z. wiss. Zool., 4 : 371-376, 1853.

Ciardi-Dupré, G.: Modification in form of human scapula during ontogenesis. Boll. 
Soc. itol. Biol. sper., $17: 348-349,1942$.

Durst-Zivković, B. and S. Davila : Strukturelle Veränderungen des Meckelschen Knorpels im Laufe der Bildung des Corpus Mandibulae. Anat. Anz., 135 : 12-23, 1974.

Dijkstra, O.H.: De ontwikkeling van het shouder blad bij den mensch. Verlag von de gewone vergaderingen der wis-en natuurkundige; Kon. Akad. Wetensch. Amsterdam, 32 : 321-332, 1923.

Dziallas, S.: Rumpf-und Extremitätenskelet eines Embryos mit Kraniorhachischisis. Z. Anat. Entwickl. Gesch., 131: 212-227, 1970.

Elmiger, P.: Die Frühentwicklung der Scapula beim Menschen. Acta Anat., 65 : 58$137,1966$.

Fawcett, E.: On ossification of the lower jaw of man. J. Anat., 39: 494-495, 1905.

Fawcett, E.: The development and ossification of the human clavicle. J. Anat., Lond., 47 : 225-234, 1913.

Fazzari, I.: Lo sviluppo della clavicola nell'uomo. Arch. ital. Anat. Embryol., 32 : 575-601, 1934.

Fischel, A.: Lehrbuch der Entwicklung des Menschen. Springer, Wien., 1929.

Fischel, A.: Grundriss der Entwicklung des Menschen. Springer, Berlin., 1937.

Florentain, P. and G. Castelain: Recherches histologiques sur le mécanisme de l'ossification de la clavicule humaine. C. R. Soc. Biol., 118 : 1545-1548, 1935.

Francis, C.C. and P.P. Werle: The appearance of centers of ossification from birth to 5 years. Am. J. Phys. Anthropol., 24 : 273-299, 1939.

Fricker, H.S.: Beitrag zur Frühentwicklung des Os coxae beim Menschen. Acta Anat., 65: 522-550, 1966.

Gardner, E. and D. J. Gray: Prenatal development of the human hip joint. Am. J. Anat., 87: 163-211, 1950.

Gardner, E. and D. J. Gray: Prenatal development of human shoulder and acromioclavicular joints. Am. J. Anat., 92: 219-276, 1953.

Gardner, E.: Osteogenesis in the human embryo and fetus. In Bourne: The biocnemistry and physiology of bone. p. 359. Academic Press INC., New York., 1956.

Gardner, E.: The embryology of the clavicle. Clin. Orthopedics, 58: 9-16, 1968.

Gardner, E. and R. O'Rahilly: The early development of the knee joint in staged human embryos. J. Anat., $102: 289-299,1968$.

Gray, D. J. and E. Gardner: Prenatal development of the human knee and superior tibiofibular joints. Am. J. Anat., 86: 235-288, 1950.

Gray, D. J. and E. Gardner: Prenatal development of the human elbow joint. Am. Am. J. Anat., 88 : 429-470, 1951.

Gray, D.J. and R. O'Rahilly: The prenatal development of the skeleton and joints of the human hand. Am. J. Anat., 101: 169-223, 1957.

Gray, D. J. and E. Gardner: The prenatal development of the human humerus. Am. J. Anat., 124 : 431-445, 1969.

Gruber, H.: Uber die Halsrippen des Menschen mit vergleich. anat. Bemerkungen. Memories de l'Acad. des Sciences de St. Petersbourg, 13, No. 2., 1869.

Grüneberg, H.: Genetical studies on the skeleton of the mouse. VII. Congenital hydrocephalus. J. Genetics, 51 : 327-358, 1953.

Hagen, W.: Die Bildung des Knorpelskelets beim menschlichen Embryo. Arch. Anat. Physiol. anat. Abt. 1, pp. 1-40, 1900.

Haines, R.W.: The development of joints. J. Anat., 81: 35-55, 1947.

Hamilton, W. J. and H.W. Mossman: Human embryology. Prenatal development of form and function. The Williams \& Wilkins Co., Baltimore., 1972.

Hanson, F.B.: The history of the earliest stages in the human clavicle. Anat. Rec., $19: 309-325,1920$.

Henke, W. and C. Reyher: Studies über die Entwicklung der Extremitäten des 
Menschen, insbesondere der Gelenkflächen. Sitzungsb. d.k. Akad. d. Wissensch., Math.-nat., $70: 217-273,1874$.

Hertig, O.: Lehrbuch der Entwicklungsgeschichte des Menschen und der Wirbeltiere. Fischer, Jena., 1906.

Hesser, C.: Beitrag zur Kenntnis der Gelenkentwicklung beim Menschen. Morphol. Jahrb., 55 : 489-567, 1926.

Hintzsche, E.: Beitrag zur Entwicklung des menschlichen Fersenbeines. Ztschr. f. mikrosk.-anat. Forsch., 21 : 531-551, 1930.

Hochstetter, F.: Über die Entwicklung der Form der menschlichen Gliedmassen. Obst. Akad. Wiss. Math-nat. Kl. Denkschr., 109: 1-35, 1952.

Javor, P.: Die Knorpelentwicklung im menschlichen Extremitätenskelet in Relation zu den Embryonalstadien. Z. Anat. Entwickl.-Gesch., 145: 227-242, 1975.

Kaneta, M.: On Meckel's cartilage. Acta Anat. Nipponica, 36 : 529-543, 1961.

Kernan, J.D.: The chondrocranium of a $20 \mathrm{~mm}$ human embryo. J. Morphol., 27:605, 1916.

Koch, A.R.: Die ${ }_{2}^{\top}$ Frühentwicklung der Clavicula beim Menschen. Acta Anat., 42: 177-212, 1960 .

Lewis, W.H.: The development of arm in man. Am. J. Anat., 1: 145-186, 1902.

Lewis, W.H.: The cartilaginous skull of a human embryo 21 milimeters in length. Contribs. Embryol., 9: 299-320, 1920.

Laurenson, R.D.: The chondrification of the human ilium. Anat. Rec., 148:197-202, $1964 \mathrm{a}$.

Laurenson, R.D.: The primary ossification of the human ilium. Anat. Rec., 148: 209-217, 1964b.

Macalister, A. Notes on the varieties and morphology of the human lachrymal bone and its accessory ossicles. Proc. Roy. Soc. Lond., 37: 229-250, 1884.

Mall, F.P.: On ossification centers in human embryos less than one hundred days old. Am. J. Anat., 5: 433-458, 1906.

Martin, P.: Contribution a l'etude des articulation des membres dhez l'embryon humain. Thèse, $56 \mathrm{pp}$. Université de Lausanne, 1929.

Menees, T.O. and L.E. Holly: The ossification in the extremities of the newborn. Am. J, Roentgenol., 28 : 389-390, 1932.

Murachi, S., Y. Sugiura, H. Nogami and J. Kou: Observation of the skeleton in human fetuses by cartilage staining. (Abstract) Seikeigeka, 39: 114, 1966.

Nauck, E. T.: Das Coracoideum der Säuger. Anat. Anz., 61 : 208-213, 1926.

Nishimura, H., K. Takano, T. Tanimura and M. Yasuda: Normal and adnormal development of human embryos: First report of the analysis of 1,213 intact embryos. Teratology, $1: 281-290,1968$.

Noback, G.L.: The use of the van Wijhe method for the staining of the cartilaginou skeleton. Anat. Rec., 11: 292-294, 1916.

Noback, C.R.: Some gross structural and quantitative aspects of the developmental anatomy of the human embryonic, fetal and circumnatal skeleton. Anat. Rec., $87: 29-51,1943$.

Noback, C.R. and G.G. Robertson: Sequences of appearance of ossification centers in the human skeleton during the first five prenatal months. Am. J. Anat., 89: $1-28,1951$.

Noback, C.R. and B.G. Böving: Skeletal system. Characterization of developmental stages : Man. In Altman, P. L. and D.S. Dittmer : Growth including reproduction and morphological development. Part IX: 293-295. Federation of American Societies for Experimental Biology, Washington, 1962.

O'Rahilly, R.: The prenatal development of the human centrale. (abstract) Anat. Rec., 118 : 334, 1954. 
O'Rahilly, R., D. J. Gray and E. Gardner: Chondrification in the hands and feet of staged human embryos. Contrib. Embryol., 36:183-192, 1957.

O'Rahilly, R. and E. Gardner: The initial appearance of ossification in staged human embryos. Am. J. Anat., 134: 291-308, 1972.

Olivier, G.: Formation du squelette des membres chez l'Homm. Vigot Freres, Editeurs, Paris., 1962.

Patten, B. M.: Human embryology. 3rd ed. McGraw-Hill Book Co., New York, 1968.

Popova-Latkina, N.V.: Entwicklung der Zwischenwirbelscheiben und der Chorda in der Embryonalzeit beim Menschen. Anat. Anz., 121: 518-536, 1967.

Röse, C.: Über die Entwicklung der Zähne des Menschen. Arch. f. mikr. Anat., 38 : $447,1891$.

Rutherford, N.C.: A contribution to the embryology of the forelimb skeleton. J. Anat., Lond., 48 : 355-377, 1914.

Salathé, B.: Über die ersten Ossificationsvorgänge an einem platten Knochen, dem Os ilium, bei menschlichen Embryonen. Acta Anat., $77: 361-397,1970$.

Schomburg, H.: Untersuchung der Entwicklung der Muskeln und Knochen des menschlichen Fusses an Serienschnitten und Rekonstructionen und unter Zuhülfenahme makroskopischer Präparation. Dissertation. Göttingen, 1900.

Schunke, G.B.: The anatomy and development of the sacro-iliac joint in man. Anat. Rec., 72 : 313-339, 1938.

Senior, H.D.: The chondrification of the human hand and foot skeleton. (abstract) Anat. Rec., 42: 35, 1929.

Sensenig, E.C.: The early development of the human vertebral column. Contrib. Embryol., 33: 21-51, 1949.

Strayer, L. M.: The embryology of the human hip joint. Yale J. Biol. Med., 16: 13$26,1943$.

Streeter, G. L. : Chondrification of the hand and foot. Carnegie Inst. Wash. Year Book, No. 28, p. 8, 1929.

Streeter, G.L.: Developmental horizons in human embryos. Descriptions of age group XIII, embryos about 4 or $5 \mathrm{~mm}$ long and age group XIV, period of identation of lens vesicle. Contrib. Embryol. 31:27-63, 1945.

Streeter, G.L.: Developmental horizons in human embryos. Descriptions of age group XV, XVI, XVII and XVIII, being the third issue of a survey of the Carnegie Collection. Contrib. Embryol. 32: 133-203, 1948.

Streeter, G.L.: Developmental horizons in human embryos. A review of the histogenesis of cartilage and bone. Contrib. Embryol., 33: 149-167, 1949.

Tanaka, O. and H. Nishimura: Individual difference of development of the several cartilage centers in human embryos. (abstract) Acta Anat. Nipponica, $44: 1$, 1969.

Tanaka, O. and H. Nishimura: Individual differences in the stage of appearance of several ossification centers in Japanese fetuses. (abstract) Teratology, 6: 121, 1972.

Tanaka, O.: Development of the scapula and the coxa in human embryos and fetuses. (abstract) Acta Anat. Nipponica, 48:78, 1973.

Teissandier, J.: L'ossification des cotes et de la colonne vertébrale chez le foetus humain. Thèse, Faculté de Médecine de Paris, 1944.

Theiler, K.: Embryonale und postnatale Entwicklung des Schädels. Encyclopedia of medical radiology. VII/I. Springer-Verlag, Berlin, 1963.

van Wijhe, J.W.: A new method for demonstrating cartilaginous microskeletons. Koninkl. Akad. van Wetenschappen te Amsterdam. Proc. meeting. May 31, 1902, 1902.

Zawisch, C.: Die frühe Histogenese der menschlichen Clavicula. Z. mikr.-anat. 
Forsch., 59 : 187-226, 1953.

Zawisch, C.: Die Morpho-und Histogenese der menschlichen Scapula. Acta Anat., 22 : $300-328,1954$.

\section{Explanation of Plate I}

Fig. 1. Chondrification in the right upper limb. H. 17.

The cartilage centers of the scapula, radius, ulna, II-V metacarpals and II-IV proximal phalanges are present.

Fig. 2. Chondrification in the bilateral lower limbs. H. 18.

The cartilage centers of the ilium, femur, tibia, fibula and II-V metatarsals are present.

Fig. 3. Chondrification in the bilateral upper limbs. H. 20. The cartilage centers of the scaphoid, triquetrum, capitate, hamate and trapezium are present.

Fig. 4. Chondrification in the right upper limb. H. 23. All cartilage centers of the hand are present.

Fig. 5. Chondrification in the whole. H. 21. 
Plate I
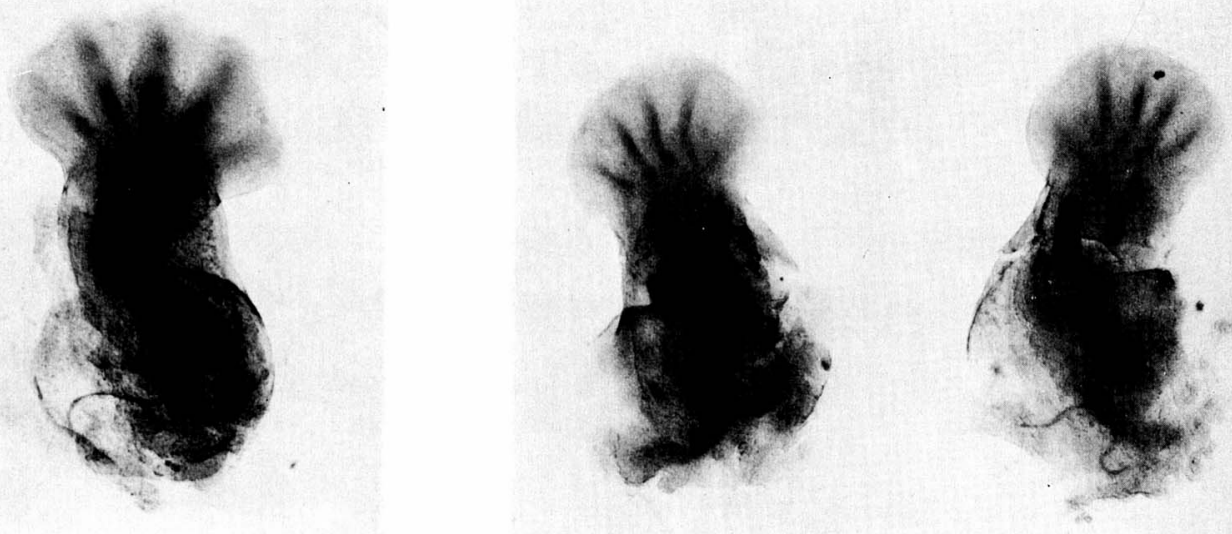

Fig. 1

Fig. 2

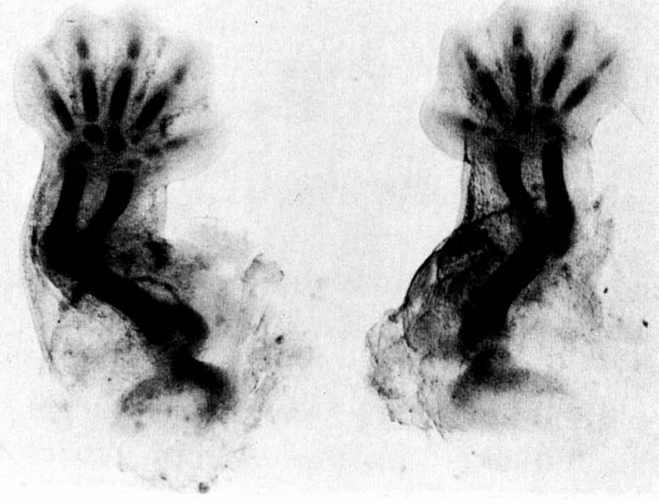

Fig. 3
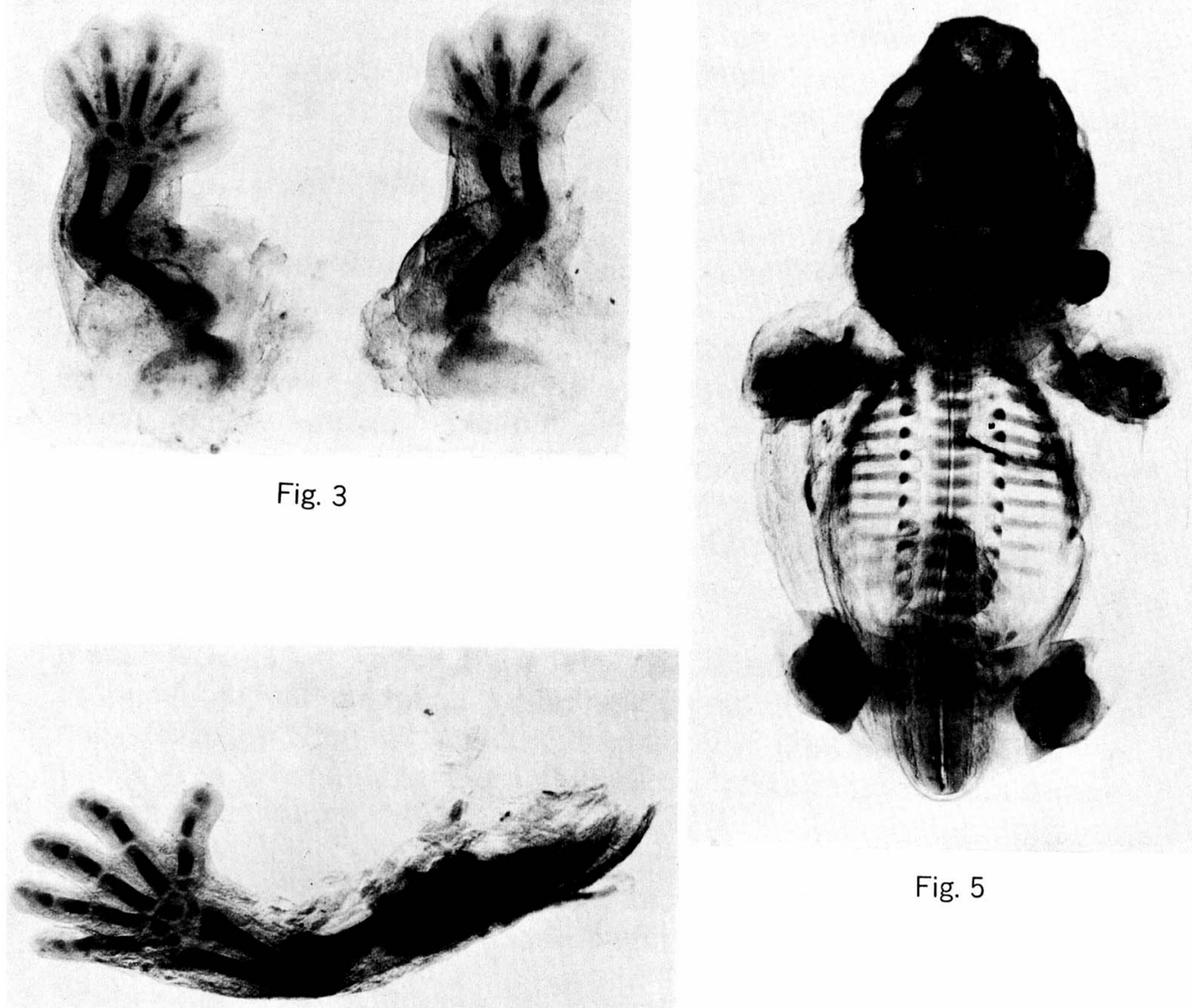

Fig. 5

Fig. 4 